\title{
Humour styles influence the perceived valence, humour, and beneficial use of depressive internet memes in depression
}

Umair Akram ( $\sim$ u.akram@shu.ac.uk)

Sheffield Hallam University

Kathryn Gardner

University of Central Lancashire, Psychology

Jennifer Drabble

Sheffield Hallam University

Nicola-Maria Jabs

University of Central Lancashire, Psychology

Article

Keywords: depression, depressive internet memes, humorous interpretation, relatability

Posted Date: March 11th, 2021

DOI: https://doi.org/10.21203/rs.3.rs-93946/v1

License: (c) (i) This work is licensed under a Creative Commons Attribution 4.0 International License.

Read Full License 


\section{Abstract}

Previous research highlights the potential benefits of engaging with depressive internet memes for those experiencing symptoms of depression, a phenomenon that can be explained in part by the humorous interpretation of depressive stimuli and a perceived sense of social support through the normalisation of depressive symptoms. This study examined whether individuals experiencing significant depressive symptoms would differ from controls in their interpretation of internet memes related to depression, whilst incorporating the mediating role of humour style. $\mathrm{N}=78$ individuals with self-reported depressive symptoms (indicating $\geq 24$ on the CES-D) and 67 controls (indicating $\leq 23$ ) rated the emotional valance, humour, relatability, shareability, and mood improving potential of 32 depressive and control internet memes (depicting general neutral or positive social commentaries). Measures of depression and humour style were also completed. The perception of humour, relatability, shareability and mood improving potential of depressive, but not control, memes were all greater amongst individuals with symptoms of depression relative to controls. However, for ratings of humour, relatability and mood improving potential, these differences were mediated by the extent of ones self-defeating humour style. These outcomes further evidence benefits of engaging with depressive internet memes for those with depression.

\section{Introduction}

The experience of depression is largely characterized by sustained negative affect (American Psychiatric Association, 2013; 2018) and co-occurs with significant emotional (e.g. emotion dysregulation; Abravanel \& Sinha, 2015; Bradley et al., 2011), cognitive (e.g. impaired memory and executive control; Rock et al., 2013; Kizilbash et al., 2002) and behavioural (e.g. social and inter-personal function; Angerman et al., 2018; Youngren \& Lewinsohn, 1980) impairments. In the general population, recent meta-analytic data evidences symptoms of depression to be highly prevalent, affecting up to $27 \%$ of individuals worldwide (Wang et al., 2017). Various predisposing, precipitating, and perpetuating factors are proposed to influence the onset of depression which may be behavioural, biological, environmental, or psychological in nature. Stress-diathesis models, one's vulnerability to depression and the experience of negative and stressful life events interact to promote the onset of a depressive episode (Colodro-Conde et al., 2018), whereas cognitive models of depression emphasise the role of disorder consistent cognitive biases of information processing (i.e. attention, interpretation and memory) in the development and maintenance of the disorder (e.g. Beck, 1991). Understanding how individuals with depressive symptoms interpret information online is particularly important given the amount of time most adults spend on the internet (approximately $4 \mathrm{hrs}$ per day in the UK; Ofcom, 2020) and social media (approximately 40 min per day in the UK; Ofcom, 2020), and the potential impact of these on mental and physical well-being (Frost \& Rickwood, 2017; Gkotsis et al., 2017; Kelly et al., 2018). Individuals' experiencing depressive symptoms may differentially interpret the various forms of online information, including humorous stimuli such as internet memes.

\subsection{Depression and humour}


The experience of humour is considered to be fundamental in maintaining adequate physical and psychological wellbeing (Martin et al., 2001). Indeed, the use of humour is consistently related to wellbeing (Martin et al., 2003; Martinez-Marti et al., 2014; Ruch et al., 2017), serves to regulate emotions (Kugler et al., 2015; Samson \& Gross, 2012; Strick et al., 2009) and is considered to be an effective coping mechanism in the face of negative and stressful life events (Labott \& Martin, 1987; Martin \& Lefcourt, 1983; Overholser, 1992; Sliter et al., 2014). Martin and colleagues (2003) identified four humour styles, two considered beneficial for wellbeing (affiliative and self-enhancing) and two which may be detrimental (self-defeating and aggressive: see Table 1 for definitions). In studies sampling healthy subjects, the positive humour styles (affiliative and self-enhancing) appear more effective in down-regulating negative and up-regulating positive emotion relative to negatively oriented humour (aggressive and self-defeating: Crawford et al., 2011). Considering this, positive humour may enhance emotion regulation whereby the accompanying positive emotion serves to facilitate the reappraisal of negative emotions (Vaillant, 2000). However, it remains unclear whether individuals with depression react to positive humour in the same way.

Table 1

Definitions of humour styles according to the Humour Styles Questionnaire*

\section{Definition}

\section{Positive:}

Affiliative

Affiliative humour involves the elicitation of. spontaneous humorous comments, jokes and humorous anecdotes which aim to: provide amusement for other people; facilitate and improve relationships; and reduce interpersonal tension.

Self- $\quad$ Self-enhancing humour encompasses a generally comical attitude towards negative enhancing and stressful life events. Its focus is intrapsychic, and this style includes using humour as a coping

strategy to regulate emotions and to reduce stress.

\section{Negative:}

Aggressive Aggressive humour involves downgrading other people. It is characterised by use of sarcasm and ridicule and contains manipulative elements which include implied threat of ridicule where the primary aim is to harm or expose other people.

Self- $\quad$ Self-defeating humour is characterised by: excessive self-disparaging humour; defeating amusing others at one's own expense to facilitate integration or gain approval; allowing oneself to be the focus of others' humour; and using humour to avoid constructive solutions to one's problems. Whilst self-defeating humour is related to low self-esteem, it is conceptually distinct from 'self-deprecation (i.e. not taking oneself too seriously, making light of one's faults and mistakes in an accepting way). Here, the latter is considered a healthier approach and is a component of affiliative humour (Dozois et al., 2008).

Note: ${ }^{*}$ Conceptualisation of humour styles as outlined by Martin et al. (2003). 
The experience of depression appears to negatively influence the cognitive and affective understanding of humour (Ukermann et al., 2007), positive responses to humorous stimuli, and the capacity to use humour as a coping strategy (Falkenberg et al., 2011). Martin and colleagues (2003) evidenced a negative relationship between positive use of humour and symptoms of depression, whereas selfdefeating humour emerged to be positively related to depressive symptoms. Furthermore, Uekermann and colleagues (2007) examined cognitive and affective humour processing in depression by comparing valance ratings and the ability to accurately determine punchlines for presented jokes amongst depressed patients and healthy controls. Here, deficits in social cognition were present in depressed patients, specifically in affective (i.e. blunted humour ratings) and cognitive (i.e. impaired accuracy) aspects of humour processing. That said, it is possible that individuals with depression react to positive humour in a different way, as compared to non-depressed individuals (Akram et al., 2020). Certainly, in the context of emotion regulation, individuals presenting with depressive symptoms appear to favour the comparative approach, where situational threat is compared with a more threatening event (i.e. it could be worse: Perchtold et al., 2019). Whereas, non-depressed individuals place greater attention on positive situational factors, detached from threat (e.g. appreciating the surroundings or accomplishments of the day: Perchtold et al., 2019). More crucially, a culmination of research tentatively suggests that efficient use of humour may serve to attenuate predictors of depression which include: blunting of positive emotion (Fava, 1999); worry, rumination and deficits in cognitive withdrawal from negative information and adverse experiences (Joormann \& D'Avanzato, 2010; Teasdale et al., 2002; Watkins \& NolenHoeksema, 2014).

Unfortunately, most studies fail to employ humour stimuli directly tied to the experience of depression (Gruber et al., 2011), relying on questionnaire measures of humour and positively valanced stimuli (i.e. amusing photographs and films). With is in mind, negatively oriented (rather than positive) humour may have greater appeal to depressed individuals when considering its salience to their specific symptom experience. In this context, internet memes related to the individual experience of depression (i.e. depressive memes) may offer a more proximal and ecological stimuli set.

\subsection{Depression and internet memes}

Internet memes are generally simulacratic in nature, visually depicting an element of a culture or behavioural system, usually in a humorous way that contextually relates to a particular demographic (see Fig. 1 for example). The term meme is based on the notion that individuals utilise creativity to conceptually manipulate an idea to the extent where it is mutated and subsequently spread through derivatives (Shifman, 2013). With that in mind, internet memes have become a crucial aspect of digital culture that are well established in the media by consistently maintaining current references that often step into cultural and political domains (Shifman, 2013).

Depressive memes in particular consist of an image and short caption, which are directly related to the experience of depressive symptoms. More specifically, these memes are predominately negative and emotional in nature, often depicting themes pertaining to death, suicide and social isolation (see Fig. 2). That said, depressive memes are typically poised in a self-defeating and humours way, with the intent of 
eliciting a degree of relatability in the target audience. Recent research found perceptual differences between subclinical depressed and non-depressed individuals in their interpretation of depressive memes (Akram et al., 2020). Here, depressed individuals reported increased perceptual ratings of humour, relatability, shareability (i.e., something they would share with others) and mood improvement potential of depressive memes when compared with non-depressed controls. These differences were mediated by deficits in the ability to deploy adaptive emotion regulation strategies. This work tentatively suggests that depressive memes promote: a humorous take on negative experiences; and perceived support by connecting with others experiencing related symptoms (Akram et al., 2020). Indeed, as people may feel uncomfortable disclosing the nature of their mental health difficulties, yet also feel the need to be understood and related to, depressive memes provide a wide reaching and alternate means of outlet.

Online self-disclosure is theorised to enhance relationships to a greater extent than face-to-face disclosures (Valkenburg \& Peter, 2009). The prevalence of online self-disclosure remains lower than offline, potentially leading to the experience of loneliness and social isolation, both risk factors for depressive symptoms (Nguyen, Bin \& Campbell, 2012). Moreover, previous work demonstrates that sharing relatable online content facilitates perceived social support, resulting in enhanced life satisfaction and self-esteem (Ellison, Steinfield \& Lampe, 2007; Bessière, Pressman, Kiesler \& Kraut, 2010). Therefore, those engaging in online self-disclosure of personal hardships via the sharing depression memes, for example, may be able to establish a contextual social support system. Indeed, internet forums dedicated to the sharing of depressive memes are often comprised of a large user base. For example, the online forum known as Reddit hosts a subreddit named depression memes which is followed by approximately one hundred and thirty-six thousand individuals.

These disparaging ideas on whether online self-disclosure is helpful or potentially damaging call for further examination and have thus far not been thoroughly investigated in the literature. The current study, therefore, examines how individuals perceive images which may be shared as a proxy of disclosure of problems or emotions commonly experienced in depressive symptoms.

\subsection{Aims of the present work}

Previous work highlights the role of emotion dysregulation in mediating perceptual differences in the observation of depressive internet memes (Akram et al., 2020). As the key function of internet memes is the elicitation of humour, the next logical step in this line of work is to examine the role of individual differences in humour styles. As such, the present research further examined the relationship between symptoms of depression and the interpretation of depressive and control memes, whilst incorporating the potential mediating role of humour style. Specifically, in partial replication of our previous work we examined group differences (high vs. low depressive symptoms) in perceptual ratings of emotional valance, humour, relatability, shareability and mood improving potential of depressive and control internet memes (depicting general neutral or positive social commentaries). Expanding on previous work, we also examined the extent to which particular humour styles (affiliative, self-enhancing, aggressive, selfdefeating) would mediate the relationship between depression and any confirmed perceptual differences. In line with previous work (Akram et al., 2020), we expected increased ratings of humour, relatability, 
shareability and mood improvement potential of depressive memes amongst those presenting symptoms of depression. Replication of these outcomes would confirm the reliability of these previous observations in two independent samples of the general population.

\section{Method}

\subsection{Participants}

A cross-sectional online questionnaire-based survey was implemented comprising of questions designed to examine humour styles, symptoms of depression and the perception of depressive and control internet memes. The survey was advertised to: members of the general population through social media, 'call for participants' (website), and 'reddit' (online forum); and students through course credit schemes. This resulted in a sample of $\mathrm{N}=250$ individuals who began the survey, and 155 respondents (mean age $=$ $26.96 \pm 9.53$, range $18-60,63.4 \%$ female) providing complete data.

\subsection{Materials}

\subsubsection{The Centre for Epidemiology Scale for Depression}

The Centre for Epidemiology Scale for Depression (CES-D: Radloff, 1977) was used to measure symptoms of depression. The measure is comprised of 20-self-report items which determine the frequency of depressive symptoms over the past two weeks. Each item is rated on a 4-point Likert-scale ranging from 0 (rarely or none of the time) to 3 (most or all of the time). The summation of each item creates a total score indicative of depression symptomatology ranging between $0-60$, where higher scores indicate greater levels of depressive symptoms. Following previous work using the CES-D (Julian et al., 2011; McDowell, 2006), a score > 23 indicates a significant level of depressive symptomatology. Internal consistency (Cronbach's a) of the scale in this study was 0.79 .

\subsubsection{The Humour Styles Questionnaire}

The Humour Styles Questionnaire (HSQ: Martin et al., 2003) was used to examine the presence of four different humour styles: affiliative (e.g. 'I laugh and joke a lot with my friends'); self-enhancing (e.g. 'My humorous outlook on life keeps me from getting overly upset or depressed about things'); aggressive (e.g. 'If someone makes a mistake, I will often tease them about it'); and self-defeating (e.g. 'I let people laugh at me or make fun at my expense more than I should'). The HSQ is comprised of 32 items, where each style of humour is determined by eight items. Respondents indicate the degree to which they agree or disagree with each item using a seven-point Likert scale (where $1=$ totally disagree and $7=$ totally agree). For each subscale, total scores range between 8-56. Higher scores indicate a stronger tendency of the respective humour style. Internal consistency (Cronbach's a) for each subscale in this study were as follows: .87 for affiliative; .82 for self-enhancing; .50 for aggressive; and .89 for self-defeating. The subscale examining the presence of an aggressive humour style was not analysed when considering the poor internal consistency observed amongst this sample. 


\subsubsection{Pictorial Stimuli}

We used a previously validated image set comprised of 16 control and 16 depressive memes (see Akram et al., 2020). The depressive memes contained affective content directly related to key features of depression (e.g. suicide, isolation, hopelessness, hypersomnia) indicated by the DSM-5 criteria for Major Depressive Disorder (American Psychiatric Association, 2013). In contrast, control memes reflected generally humorous social commentaries that were unrelated to depression (see Fig. 1 for example). Image size was standardised for presentation (640 ×640px).

\subsection{Procedure}

Ethical approval was granted by the [Masked_for_Review] Research Ethics Committee. This experiment was conducted in accordance with the Declaration of Helsinki, and all participants gave their written informed consent before participation. Participants completed the online questionnaire, in which they were presented the series of 32 pictorial memes in randomized order. Using a 5-point likert scale ranging from strongly disagree $(=1)$ to agree $(=5)$, participants reported the extent to which each meme was considered to be: positive; relatable; funny; something they would share with other people; and something that would make a person with depression feel good. In addition, participants categorically indicated whether each meme was perceived to be more related to anxiety, depression, or neither. Following the pictorial meme ratings, the CES-D and HSQ was administered. Once complete, participants were debriefed about the nature of the study.

\subsection{Statistical analyses}

\subsubsection{Participant Grouping}

Participants were first grouped based on the severity of reported depression symptoms. Using the CES-D, individuals with a score of: $\leq 23$ (Mean $=16.88 \pm 4.33$; Range $=7-23$ ) were placed into the control group $(n=67$ : mean age $=28.55 \pm 9.09 ; 71 \%$ female); and $\geq 24$ (Mean $=33.05 \pm 5.34 ;$ Range $=24-45)$ into the depression symptoms group $(n=78$ : mean age $=25.60 \pm 9.75 ; 65 \%$ female). Following, mean perception ratings for depressive and control memes were calculated for the whole sample and each individual group. This was conducted for each parameter assessed. Specifically: a) valance, as assessed by asking the extent to which each meme was considered to be positive (i.e. valance); b) humor (or funniness); c) relatability; d) shareability; and e) something that would make a person with depression feel good (DEPFEEL).

\subsubsection{Analysis}

A series of 2 (group: control vs. depression symptoms) x 2 (meme type: depressive vs. control) mixed measures ANOVA's were employed, with rating scores for each parameter as dependent variables. This was conducted to assess the main effects of group and meme type, as well as the group $\mathrm{x}$ meme type interaction. Moreover, simple effects analyses were performed to determine any significant interactions as appropriate. This was followed by a series of sequential logistic regression analyses to determine 
whether group (control vs. depression symptoms) differences in the perception of depressive memes were mediated by humor style. For example, valence ratings (step 1), and humor style subscales (affiliative, self-enhancing, self-defeating: step 2) were entered as predictor variables. Significance was considered at the $\mathrm{P}<.05$ level.

\section{Results}

Mean scores on the CES-D and HSQ, as well as meme ratings, are displayed in Table 1. As expected, those in the depression group displayed significantly greater symptoms of depression $t(1,143)=-19.80, p$ $<.001$. However, groups did not differ in age $t(1,143)=1.80, p=.074$ nor sex $X^{2}=0.273, p=.601$. 
Table 2

Ratings of memes for the control and depression symptoms groups whilst observing depressive and control memes (means \pm standard deviation)

\section{Depressive Memes}

$\begin{array}{ll}\text { Depression Symptoms }(n= & \begin{array}{l}\text { Control Group }(n= \\ 67)\end{array}\end{array} \quad \begin{array}{lll}\text { Cohens' } \\ \text { d8 }\end{array}$

\section{Ratings:}

\begin{tabular}{|c|c|c|c|c|c|}
\hline Valence & $2.22 \pm 0.99$ & $2.13 \pm 0.67$ & -0.61 & .544 & 0.11 \\
\hline Humor & $3.81 \pm 0.95$ & $3.02 \pm 0.94$ & -5.05 & .001 & 0.84 \\
\hline Relatability & $4.13 \pm 0.75$ & $2.99 \pm 0.89$ & -8.31 & .001 & 1.39 \\
\hline Shareability & $3.01 \pm 1.21$ & $2.28 \pm 1.02$ & -3.87 & .001 & 0.65 \\
\hline \multirow[t]{2}{*}{ DEPFEEL } & $3.06 \pm 1.02$ & $2.48 \pm 0.93$ & -3.57 & .001 & 0.60 \\
\hline & Control Memes & & & & \\
\hline Valence & $3.57 \pm 0.63$ & $3.66 \pm 0.52$ & 0.90 & .368 & 0.16 \\
\hline Humor & $3.83 \pm 0.83$ & $3.53 \pm 0.74$ & 1.09 & .280 & 0.40 \\
\hline Relatability & $3.07 \pm 0.75$ & $3.19 \pm 0.72$ & 0.97 & .333 & 0.16 \\
\hline Shareability & $2.77 \pm 1.00$ & $2.75 \pm 1.00$ & -0.07 & .947 & 0.02 \\
\hline DEPFEEL & $2.98 \pm 0.85$ & $3.10 \pm 0.68$ & 0.94 & .350 & 0.16 \\
\hline CES-D & $33.05 \pm 5.34$ & $16.88 \pm 4.34$ & -19.80 & & 3.29 \\
\hline \multicolumn{6}{|l|}{ HSQ: } \\
\hline Affiliative & $20.48 \pm 8.53$ & $21.15 \pm 9.07$ & 0.45 & .652 & 0.08 \\
\hline Self-enhancing & $31.35 \pm 9.20$ & $26.67 \pm 8.82$ & -3.11 & .002 & 0.52 \\
\hline Aggressive & $32.51 \pm 6.61$ & $33.85 \pm 4.99$ & 1.36 & .177 & 0.23 \\
\hline Self-defeating & $25.37 \pm 11.04$ & $33.19 \pm 1.14$ & 4.32 & .001 & 1.00 \\
\hline \multicolumn{6}{|l|}{ DERS-SF: } \\
\hline Nonacceptance & $3.54 \pm 1.09$ & $2.40 \pm 1.14$ & -6.12 & .001 & 1.02 \\
\hline Goals & $4.24 \pm 0.87$ & $3.21 \pm 0.94$ & -6.81 & .001 & 1.14 \\
\hline Impulse & $2.57 \pm 1.23$ & $1.71 \pm 0.83$ & -4.88 & .001 & 0.82 \\
\hline Awareness & $2.78 \pm 1.12$ & $2.24 \pm 0.96$ & -3.07 & .001 & 0.52 \\
\hline Strategies & $3.61 \pm 1.02$ & $2.35 \pm 0.96$ & -7.58 & .001 & 1.27 \\
\hline
\end{tabular}




\section{Depressive Memes}

Clarity

$2.86 \pm 1.08$

$2.13 \pm 0.80$

$-4.44$

.001

0.77

Note: DEPFEEL, ratings of the extent to which memes would make someone with depression feel good; PHQ-9, Patient Health Questionnaire Depression Scale; DERS-SF, Difficulties in Emotion Regulation Scale Short Form.

$\star$ Sig at $<.01, * *<.001$

\subsection{Valance}

The results revealed a significant main effect of meme type $(F(1,143)=394.22, p=.001)$ on ratings of valence. However, no main effects of group $(F(1,143)=0.00, p=.998)$ or group $x$ meme type interactions $(F(1,143)=1.45, p=.230)$ were determined.

\subsection{Humour}

The results demonstrated a significant main effect of group $(F(1,143)=8.39, p=.004)$, but not meme-type $(F(1,143)=0.20, p=.654)$ on humour ratings. Moreover, a significant group $x$ meme type interaction demonstrated that, compared to control participants $(3.02 \pm 0.94)$, individuals experiencing symptoms of depression $(3.81 \pm 0.95)$ rated the depressive memes as significantly more humorous, $F(1,143)=26.06, p$ $=.001$. Individual analysis of humour ratings for each meme type revealed a significant difference between individuals experiencing symptoms of depression and control participants for depressive memes only $(t(143)=-5.05, p=.001)$. No group differences were observed for neutral memes $(t(143)=-1.09, p=.280)$.

\subsection{Relatability}

The results revealed a significant main effect of group $(F(1,143)=27.07, p=.001)$ and meme type $F(1,143)=26.18, p=.001)$ on ratings of relatability. Moreover, a significant group $x$ meme type interaction demonstrated that, compared to control participants $(2.99 \pm 0.89)$, the depression symptoms group (4.13 \pm 0.75 ) rated depressive memes as significantly more relatable, $F(1,143)=53.37, p=.001$. Individual analysis of relatability ratings for each meme type revealed a significant difference between individuals experiencing symptoms of depression and control participants for depressive memes only $(t(143)=-8.31$, $p=.001)$. No group differences were observed for neutral memes $(t(143)=0.97, p=.333)$.

\subsection{Shareability}

The results demonstrated a significant main effect of group $(F(1,143)=6.34, p=.013)$, but not meme-type $(F(1,143)=1.36, p=.245)$ on the likelihood of sharing memes with other people. Moreover, a significant group $x$ meme type interaction demonstrated that, compared to control participants $(2.28 \pm 1.02)$, the depression symptoms group (3.01 \pm 1.21$)$ rated depressive memes as significantly more sharable, 
$F(1,143)=12.60, p=.001$. Individual analysis of shareability ratings for each meme type revealed a significant difference between individuals experiencing symptoms of depression and control participants for depressive memes only $(t(143)=-3.87, p=.001)$. No group differences were observed for neutral memes $(t(143)=-0.07, p=.947)$.

\subsection{DEPFEEL}

The results revealed significant main effects of group $(F(1,143)=4.00, p=.047)$ and meme-type, $F(1,143)$ $=8.56 \mathrm{p}=.004$. Moreover, a significant group $\mathrm{x}$ meme type interaction demonstrated that, compared to control participants $(2.19 \pm 1.02)$, the depression symptoms group $(2.79 \pm 0.98)$ rated depressive memes as significantly more likely to improve the mood of someone with depression, $F(1,143)=14.74, p=.001$. Individual analysis of ratings for each meme type revealed a significant difference between individuals experiencing symptoms of depression and control participants for depressive memes only $(t(143)=-3.57$ $p=.001)$. No group differences were observed for neutral memes $(t(143)=-0.94, p=.350)$.

\subsection{Mediating role of humour style}

Sequential logistic regression analysis demonstrated that the extent of humour ratings whilst observing depressive memes (step 1: 20\% variance explained; see Table 3 panel a) significantly predicted group status (control vs. depression symptoms). However, after accounting for each humor style (affiliative, self-enhancing, self-defeating), humour ratings along with self-enhancing and self-defeating humour styles remained the only significant predictor of group status in the following step (step 2: 38\% variance). Interestingly, this pattern of results was mirrored for individual analysis of shareability and DEPFEEL, whereby humour ratings along with self-enhancing and self-defeating humour styles remained the only significant predictor of group status (see Table 3 panels c-d respectively). Finally, whilst the relatability of depressive memes (step 1: $31 \%$ variance explained; see Table 3 panel b) significantly predicted group status, after accounting for each humor style, humour ratings and the self-enhancing humour style remained the only significant predictor of group status in the following step (step 2: $38 \%$ variance). 
Table 3

Sequential logistic regression analyses with group status (control vs. depression symptoms) as the dependant variable; meme ratings (Step 1) and humour style (Step 2) subscales as predictors.

$\begin{array}{lllll}\text { Predictors } & \mathbf{R}^{2} & \boldsymbol{\beta} & \text { Wald } & \text { Sig. }\end{array}$

\section{[A]}

Step 1

.20

0.86

19.48

$.001^{\star \star}$

Humour

Step 2

.38

Humour

0.67

9.13

$.003^{*}$

Affiliative

$-0.2$

0.80

.372

Self-enhancing

0.11

15.50

$.001^{\star *}$

Self-defeating

$-0.7$

10.29

$.001^{\star \star}$

[B]

Step 1

.31

Relatable

1.61

33.15

$.001^{\star \star}$

Step 2

.38

Relatable

1.39

21.28

$.001^{\star *}$

Affiliative

$-0.03$

1.42

.234

Self-enhancing

0.10

11.40

$.001^{\star *}$

Self-defeating

$-0.04$

3.08

.079

[C]

Step 1

.13

Shareable

0.60

12.77

$.001^{\star \star}$

Step 2

.35

Shareable

0.44

5.43

$.020 *$

Affiliative

$-0.03$

1.35

.246

Self-enhancing

0.11

17.17

$.001^{\star \star}$

Self-defeating

$-0.07$

11.76

$.001^{\star \star}$

[D]

Step 1 


\begin{tabular}{|lllll|}
\hline Predictors & $\mathbf{R}^{\mathbf{2}}$ & $\boldsymbol{\beta}$ & Wald & Sig. \\
\hline DEPFEEL & & 0.61 & 11.06 & $.001^{\star *}$ \\
\hline Step 2 & .36 & & & \\
\hline DEPFEEL & & 0.60 & 7.46 & $.006^{*}$ \\
\hline Affiliative & -0.03 & 1.51 & .218 \\
\hline Self-enhancing & 0.11 & 18.29 & $.001^{\star *}$ \\
\hline $\begin{array}{l}\text { Self-defeating } \\
\text { Note: DEPFEEL, ratings of the extent to which memes would make someone with depression feel } \\
\text { good; R': Nagelkerke R Square. } \\
\text { *Sig at }<.01, * \star<.001\end{array}$ & -0.08 & 14.60 & $.001^{\star *}$ \\
\hline
\end{tabular}

Based on the outcomes of the regression analyses, the mediating effects of humour styles were further examined using the MEDMOD plugin for Jamovi. Bootstrapping with 1000 bias-corrected and accelerate resamples and $95 \%$ confidence intervals were used, and the Sobel test $(\mathrm{z})$ was used to indicate the hypothesized mediation effects. As demonstrated in Table 4, the results demonstrated significant direct effects between meme ratings and group status. However, a series of indirect effects of three types of meme rating (humour, sharability, and DEPFEEL but not relatability) on group-status via depression were only observed for self-defeating, but not self-enhancing humour. Therefore, compared to non-depressed controls, individuals experiencing symptoms of depression perceive depressive memes as more humorous, relatable, and shareable with the potential of improving the mood of a person with depression. However, these differences in interpretation (for ratings of humour, sharability, and DEPFEEL) appear to be mediated by one's level of self-defeating humour style. 
Table 4

Examination of the mediating effect of humour style, with group status (control vs. depression symptoms) as the dependent variable (DV) and meme ratings as the independent variables (IV).

\begin{tabular}{|c|c|c|c|c|c|c|c|c|}
\hline \multirow[t]{2}{*}{ IV } & \multirow[t]{2}{*}{ Mediator } & \multirow[t]{2}{*}{ DV } & \multirow{2}{*}{$\begin{array}{l}\text { Z: Total } \\
\text { effect (c } \\
\text { path) }\end{array}$} & \multirow{2}{*}{$\begin{array}{l}\text { Z: Direct } \\
\text { effect (c' } \\
\text { path) }\end{array}$} & \multicolumn{2}{|c|}{$\begin{array}{l}\text { Total indirect } \\
\text { effect }\end{array}$} & \multirow[t]{2}{*}{$\beta$} & \multirow[t]{2}{*}{$\mathbf{P}$} \\
\hline & & & & & $\begin{array}{l}\text { Point } \\
\text { est. }\end{array}$ & $95 \% \mathrm{Cl}$ & & \\
\hline \multicolumn{9}{|l|}{ [A] } \\
\hline \multirow[t]{3}{*}{ Humour } & $\begin{array}{l}\text { Self- } \\
\text { enhancing }\end{array}$ & Group & -0.30 & & -.004 & $\begin{array}{l}-.034 \\
.024\end{array}$ & -.009 & .764 \\
\hline & $\begin{array}{l}\text { Self- } \\
\text { defeating }\end{array}$ & Group & $3.14 *$ & & .064 & $\begin{array}{l}.024 \\
.105\end{array}$ & .129 & .002 \\
\hline & & & & $3.08 *$ & .130 & $\begin{array}{l}.049 \\
.215\end{array}$ & .261 & .002 \\
\hline \multicolumn{9}{|l|}{ [B] } \\
\hline \multirow[t]{2}{*}{ Relatable } & $\begin{array}{l}\text { Self- } \\
\text { enhancing }\end{array}$ & Group & 0.63 & & .006 & $\begin{array}{l}-.014 \\
.028\end{array}$ & .013 & .530 \\
\hline & & & & $8.69 * \star$ & .288 & $\begin{array}{l}.218 \\
.345\end{array}$ & .558 & .001 \\
\hline \multicolumn{9}{|l|}{ [C] } \\
\hline \multirow[t]{3}{*}{ Sharable } & $\begin{array}{l}\text { Self- } \\
\text { enhancing }\end{array}$ & Group & -1.19 & & -.015 & $\begin{array}{l}-.040 \\
.010\end{array}$ & -.035 & .233 \\
\hline & $\begin{array}{l}\text { Self- } \\
\text { defeating }\end{array}$ & Group & $3.71^{\star \star}$ & & .060 & $\begin{array}{l}.028 \\
.091\end{array}$ & .139 & .001 \\
\hline & & & & $2.70 *$ & .085 & $\begin{array}{l}.024 \\
.148\end{array}$ & .197 & .007 \\
\hline \multicolumn{9}{|l|}{ [D] } \\
\hline \multirow[t]{3}{*}{ DEPFEEL } & $\begin{array}{l}\text { Self- } \\
\text { enhancing }\end{array}$ & Group & -1.35 & & -.021 & $\begin{array}{l}-.050 \\
.010\end{array}$ & -.041 & .176 \\
\hline & $\begin{array}{l}\text { Self- } \\
\text { defeating }\end{array}$ & Group & $2.86^{\star}$ & & .054 & $\begin{array}{l}.017 \\
.088\end{array}$ & .107 & .003 \\
\hline & & & & $2.88^{\star}$ & .07 & $\begin{array}{l}.034 \\
.180\end{array}$ & .213 & .004 \\
\hline \multicolumn{9}{|c|}{$\begin{array}{l}\text { Note: P, Sobel test; Mediation model, } 1000 \text { bootstrap samples; Confidence that do not include zero are } \\
\text { significant at the } .05 \text { level. }\end{array}$} \\
\hline$\star$ Sig at $<$. & $1 * *<.001$ & & & & & & & \\
\hline
\end{tabular}




\section{Discussion}

The present research examined the relationship between symptoms of depression and the interpretation of depressive and control memes, whilst incorporating the potential mediating role of humour style. In line with previous work, with the exception of valence ratings, groups differed in their interpretation of depressive memes (Akram et al., 2020). More specifically, the perception of humour, relatability, shareability and mood improving potential of depressive, but not control, memes were all greater amongst individuals with symptoms of depression relative to non-depressed controls. However, for ratings of humour, relatability and mood improving potential, these differences were mediated by the extent of ones self-defeating humour style.

Humour which is positively orientated appears to reduce emotional distress and emotion dysregulation in non-depressed individuals (Martin et al., 1983; Newman et al., 1996; Samson et al., 2012; Vaillnet et al., 2000). However, the current outcomes highlight benefits of negative humour for those experiencing depressive symptoms. Despite the negative and self-defeating scenarios presented in depressive memes, their contextual salience to depressed individuals may be considered somewhat positive. Certainly, by definition, internet memes provide humorous social commentaries which contextually relate to their target demographic (Davison et al., 2012). With that in mind, recent work evidenced perceived benefits related to online interaction with affective internet memes (Akram et al., 2020; Kariko \& Anasih, 2017). In a survey of 133 college students, $47 \%$ of individuals reported engaging with memes as a way of alleviating psychiatric symptoms (Kariko \& Anasih, 2017). In this study, humour and relatability associated with dark and self-deprecating memes were reported to function as a coping mechanism, allowing individuals to laugh at their problems whilst connecting with others in the same situation. Moreover, comparison of depressed individuals and controls found perceptual differences in the interpretation of internet memes illustrating the experience of depression (e.g. death, suicide, isolation, hopelessness, hyper/insomnia: Akram et al., 2020). Here, the perception of humour, relatability, shareability and mood improving potential of these memes were significantly higher amongst those presenting with depressive symptoms. Engaging with internet memes related to one's specific difficulties may potentially come with beneficial consequences by theoretically accentuating a humorous take on a negative experience, and a perceived sense of social support through the normalisation of depressive symptoms. Internet memes visually portray the debilitating nature of depression, which verbally, may be difficult to describe. Considering depressed individuals benefit from social support through online interaction (LaRose et al., 2001), by engaging with depressive memes (e.g. sharing, liking) depressed individuals may possibly form social and emotional bonds with others that are perceived as socially supportive (Akram et al., 2020).

With regards to the role of humour styles, generally, positive affiliative and self-enhancing humour are considered beneficial for wellbeing, whereas negative self-defeating and aggressive styles are and considered detrimental (Martin et al., 2001). According to recent meta-analytic data, depressed individuals display an increased propensity to engage in negative (i.e. aggressive and self-defeating) rather than positive (affiliative, self-enhancing) humour (Schneider et al., 2018). However, the present outcomes found the presentation of humour styles to be somewhat mixed across groups. Here, those 
experiencing symptoms of depression reported greater use of positive self-enhancing humour and less use of self-defeating humour when compared with controls. More crucially, our data suggests perceptual differences in the observation of depressive memes were largely mediated by the extent to which individuals presented self-defeating humour styles. Here, depressive memes were more favourable in those displaying depressive symptoms and reduced reports of self-defeating humour. These outcomes make sense when considering the nature of this style of humour. Indeed, depressive memes present a humorous take on negative and stressful life events and may serve as an outlet for those who would otherwise fail to use self-enhancing humour in day to day life. In the context of self-defeating humour, depressive memes substantially differ in nature (i.e. self-disparaging behaviour to gain approval of others, allowing oneself to be the focus of others' humour). Rather, as aforementioned, depressive memes allow a mutual socially supportive understanding to form with other people who share the same experience.

Several limitations of the current study should be noted. It is possible that some individuals observe depressive memes rather frequently and exposure to this type of content may lead to de-sensitisation and self-trivialisation as a depressive state is portrayed in a less meaningful way. The present study used a previously validated set of depressive memes (Akram \& colleagues, 2020), but future work should replicate these findings using an alternative culturally and topically current set of memes and in a sample meeting the diagnostic criteria for major depressive disorder where deficits in cognitive biases may be more pronounced.

In line with previous work, the perception of humour, relatability, shareability and mood improving potential of depressive memes were all greater in individuals displaying depressive symptoms when compared with controls. These differences, for ratings of humour, relatability and mood improving potential, were however mediated by the extent of one's self-defeating humour style. These findings suggest that internet memes related to depression may potentially be beneficial for individuals experiencing subclinical depressive symptoms in the community, particularly in those presenting lower levels of self-defeating humour. Previous work suggests perceptual differences in the observation of depressive memes to be mediated by deficits in the ability to deploy adaptive emotion regulation strategies (Akram et al., 2020). Here, we expand on this work by highlighting the mediating role of selforiented humour. Further experimental and longitudinal investigations are however required to substantiate these claims. Here, observing longitudinal alterations in depressive symptomology in those who frequently observe depressive memes would be of particular interest to determine any benefits or detriments of internet meme use. Whereas, in depressed individuals who do not engage with internet memes, experimental exposure to depressive or control memes may be explored in the context of symptom severity.

\section{Declarations}

\section{Competing interests:}


The authors declare no competing interests.

\section{References}

Abravanel BT, Sinha R. Emotion dysregulation mediates the relationship between lifetime cumulative adversity and depressive symptomatology. Journal of psychiatric research. 2015 Feb 1;61:89-96.

Akram U, Drabble J, Cau G, Hershaw F, Rajenthran A, Lowe M, Trommelen C, Ellis JG. Exploratory study on the role of emotion regulation in perceived valence, humour, and beneficial use of depressive internet memes in depression. Scientific Reports. 2020 Jan 21;10(1):1-8.

American Psychiatric Association. Diagnostic and statistical manual of mental disorders (DSM-5®). (American Psychiatric Pub,) 2013.

Angermann CE, Ertl G. Depression, Anxiety, and Cognitive Impairment. Current heart failure reports. 2018 Dec 1;15(6):398-410.

Beck AT. Cognitive therapy and the emotional disorders. Penguin; 1979 Oct 1.

Beevers CG. Cognitive vulnerability to depression: A dual process model. Clinical psychology review. 2005 Nov 1;25(7):975-1002.

Bessiere K, Kiesler S, Kraut R, Boneva BS. Effects of Internet use and social resources on changes in depression. Information, Community \& Society. 2008 Feb 1;11(1):47-70.

Blackwell SE, Holmes EA. Modifying interpretation and imagination in clinical depression: A single case series using cognitive bias modification. Applied Cognitive Psychology: The Official Journal of the Society for Applied Research in Memory and Cognition. 2010 Apr;24(3):338-50.

Bradley BD, DeFife JA, Guarnaccia C, Phifer MJ, Fani MN, Ressler KJ, Westen D. Emotion dysregulation and negative affect: association with psychiatric symptoms. The Journal of clinical psychiatry. 2011 May;72(5):685.

Butler G, Mathews A. Cognitive processes in anxiety. Advances in behaviour research and therapy. 1983 Jan 1;5(1):51-62.

Crawford SA, Caltabiano NJ. Promoting emotional well-being through the use of humour. The Journal of Positive Psychology. 2011 May 1;6(3):237-52.

Ellison NB, Steinfield C, Lampe C. The benefits of Facebook "friends:" Social capital and college students' use of online social network sites. Journal of computer-mediated communication. 2007 Jul 1;12(4):114368.

Ellsworth PC, Scherer KR. Appraisal processes in emotion. Oxford University Press; 2003. 
Everaert J, Duyck W, Koster EH. Attention, interpretation, and memory biases in subclinical depression: A proof-of-principle test of the combined cognitive biases hypothesis. Emotion. 2014 Apr;14(2):331.

Frost RL, Rickwood DJ. A systematic review of the mental health outcomes associated with Facebook use. Computers in Human Behavior. 2017 Nov 1;76:576-600.

Gkotsis G, Oellrich A, Velupillai S, Liakata M, Hubbard TJ, Dobson RJ, Dutta R. Characterisation of mental health conditions in social media using Informed Deep Learning. Scientific reports. 2017 Mar 22;7:45141.

Hindash AH, Amir N. Negative interpretation bias in individuals with depressive symptoms. Cognitive therapy and research. 2012 Oct 1;36(5):502-11.

Joormann J, Waugh CE, Gotlib IH. Cognitive bias modification for interpretation in major depression: Effects on memory and stress reactivity. Clinical Psychological Science. 2015 Jan;3(1):126-39.

Julian LJ, Gregorich SE, Tonner C, Yazdany J, Trupin L, Criswell LA, Yelin E, Katz PP. Using the Center for Epidemiologic Studies Depression Scale to screen for depression in systemic lupus erythematosus. Arthritis care \& research. 2011 Jun;63(6):884-90.

Kaufman EA, Xia M, Fosco G, Yaptangco M, Skidmore CR, Crowell SE. The Difficulties in Emotion Regulation Scale Short Form (DERS-SF): Validation and replication in adolescent and adult samples. Journal of Psychopathology and Behavioral Assessment. 2016 Sep 1;38(3):443-55.

Kelly Y, Zilanawala A, Booker C, Sacker A. Social media use and adolescent mental health: Findings from the UK Millennium Cohort Study. EClinicalMedicine. 2018 Dec 1;6:59-68.

Kizilbash AH, Vanderploeg RD, Curtiss G. The effects of depression and anxiety on memory performance. Archives of clinical neuropsychology. 2002 Jan 1;17(1):57-67.

Kugler L, Kuhbandner C. That's not funny!-But it should be: effects of humorous emotion regulation on emotional experience and memory. Frontiers in psychology. 2015 Aug 28;6:1296.

Labott SM, Martin RB. The stress-moderating effects of weeping and humor. Journal of Human Stress. 1987 Dec 1;13(4):159-64.

Lawson C, MacLeod C. Depression and the interpretation of ambiguity. Behaviour research and therapy. 1999 May 1;37(5):463-74.

MacLeod C, Cohen IL. Anxiety and the interpretation of ambiguity: A text comprehension study. Journal of Abnormal Psychology. 1993 May;102(2):238.

Martin RA, Lefcourt HM. Sense of humor as a moderator of the relation between stressors and moods. Journal of personality and social psychology. 1983 Dec;45(6):1313. 
Martin RA, Puhlik-Doris P, Larsen G, Gray J, Weir K. Individual differences in uses of humor and their relation to psychological well-being: Development of the Humor Styles Questionnaire. Journal of research in personality. 2003 Feb 1;37(1):48-75.

Martin RA, Puhlik-Doris P, Larsen G, Gray J, Weir K. Individual differences in uses of humor and their relation to psychological well-being: Development of the Humor Styles Questionnaire. Journal of research in personality. 2003 Feb 1;37(1):48-75.

Martin RA. Humor, laughter, and physical health: methodological issues and research findings. Psychological bulletin. 2001 Jul;127(4):504.

Martínez-Martí ML, Ruch W. Character strengths and well-being across the life span: data from a representative sample of German-speaking adults living in Switzerland. Frontiers in psychology. 2014 Nov 4;5:1253.

Mathews A, MacLeod C. Cognitive vulnerability to emotional disorders. Annu. Rev. Clin. Psychol.. 2005 Apr 27;1:167-95.

McDowell I. Measuring health: a guide to rating scales and questionnaires. Oxford University Press, USA; 2006.

Mogg K, Bradbury KE, Bradley BP. Interpretation of ambiguous information in clinical depression. Behaviour research and therapy. 2006 Oct 1;44(10):1411-9.

Newman MG, Stone AA. Does humor moderate the effects of experimentally-induced stress?. Annals of behavioral medicine. 1996 Jun 1;18(2):101-9.

Nguyen M, Bin YS, Campbell A. Comparing online and offline self-disclosure: A systematic review. Cyberpsychology, Behavior, and Social Networking. 2012 Feb 1;15(2):103-11.

Ofcom UK. Online Nation 2020 Report. 2020. https://www.ofcom.org.uk/research-and-data/internet-andon-demand-research/online-nation

Overholser JC. Sense of humor when coping with life stress. Personality and individual differences. 1992 Jul 1;13(7):799-804.

Perchtold CM, Weiss EM, Rominger C, Feyaerts K, Ruch W, Fink A, Papousek I. Humorous cognitive reappraisal: More benign humour and less" dark" humour is affiliated with more adaptive cognitive reappraisal strategies. PloS one. 2019 Jan 31;14(1):e0211618.

Rock PL, Roiser JP, Riedel WJ, Blackwell AD. Cognitive impairment in depression: a systematic review and meta-analysis. Psychological medicine. 2014 Jul 1;44(10):2029. 
Ruch W, Hofmann J. Fostering humour. In: Proctor C, editor. Positive psychology interventions in practice. Cham: Springer International Publishing; 2017. p. 65-80.

Samson AC, Gross JJ. Humour as emotion regulation: The differential consequences of negative versus positive humour. Cognition \& emotion. 2012 Feb 1;26(2):375-84.

Samson AC, Gross JJ. Humour as emotion regulation: The differential consequences of negative versus positive humour. Cognition \& emotion. 2012 Feb 1;26(2):375-84.

Samson, A. C., \& Gross, J. J. (2014). The dark and light sides of humor. An Emotion-Regulation Perspective. In J. Gruber, \& J. T. Moskowitz (Eds.), Positive emotion. integrating the light sides and dark sides (pp. 169-182). New York, NY: Oxford University Press.

Schneider M, Voracek M, Tran US. "A joke a day keeps the doctor away?" Meta-analytical evidence of differential associations of habitual humor styles with mental health. Scandinavian journal of psychology. 2018 Jun;59(3):289-300.

Shifman L. Memes in a digital world: Reconciling with a conceptual troublemaker. Journal of computermediated communication. 2013 Apr 1;18(3):362-77.

Sliter M, Kale A, Yuan Z. Is humor the best medicine? The buffering effect of coping humor on traumatic stressors in firefighters. Journal of Organizational Behavior. 2014 Feb;35(2):257-72.

Strick M, Holland RW, Van Baaren RB, Van Knippenberg AD. Finding comfort in a joke: Consolatory effects of humor through cognitive distraction. Emotion. 2009 Aug;9(4):574.

Vaillant GE. Adaptive mental mechanisms: Their role in a positive psychology. American psychologist. 2000 Jan;55(1):89.

Valkenburg, P., \& Peter, J. (2009). Social Consequences Of The Internet For Adolescents. Current Directions In Psychological Science, 18(1), 1-5.

Wang J, Wu X, Lai W, Long E, Zhang X, Li W, Zhu Y, Chen C, Zhong X, Liu Z, Wang D. Prevalence of depression and depressive symptoms among outpatients: a systematic review and meta-analysis. BMJ open. 2017 Aug 1;7(8):e017173.

Youngren MA, Lewinsohn PM. The functional relation between depression and problematic interpersonal behavior. Journal of abnormal psychology. 1980 Jun;89(3):333.

\section{Figures}




\section{When you sneeze so hard, your moustache changes lips:}

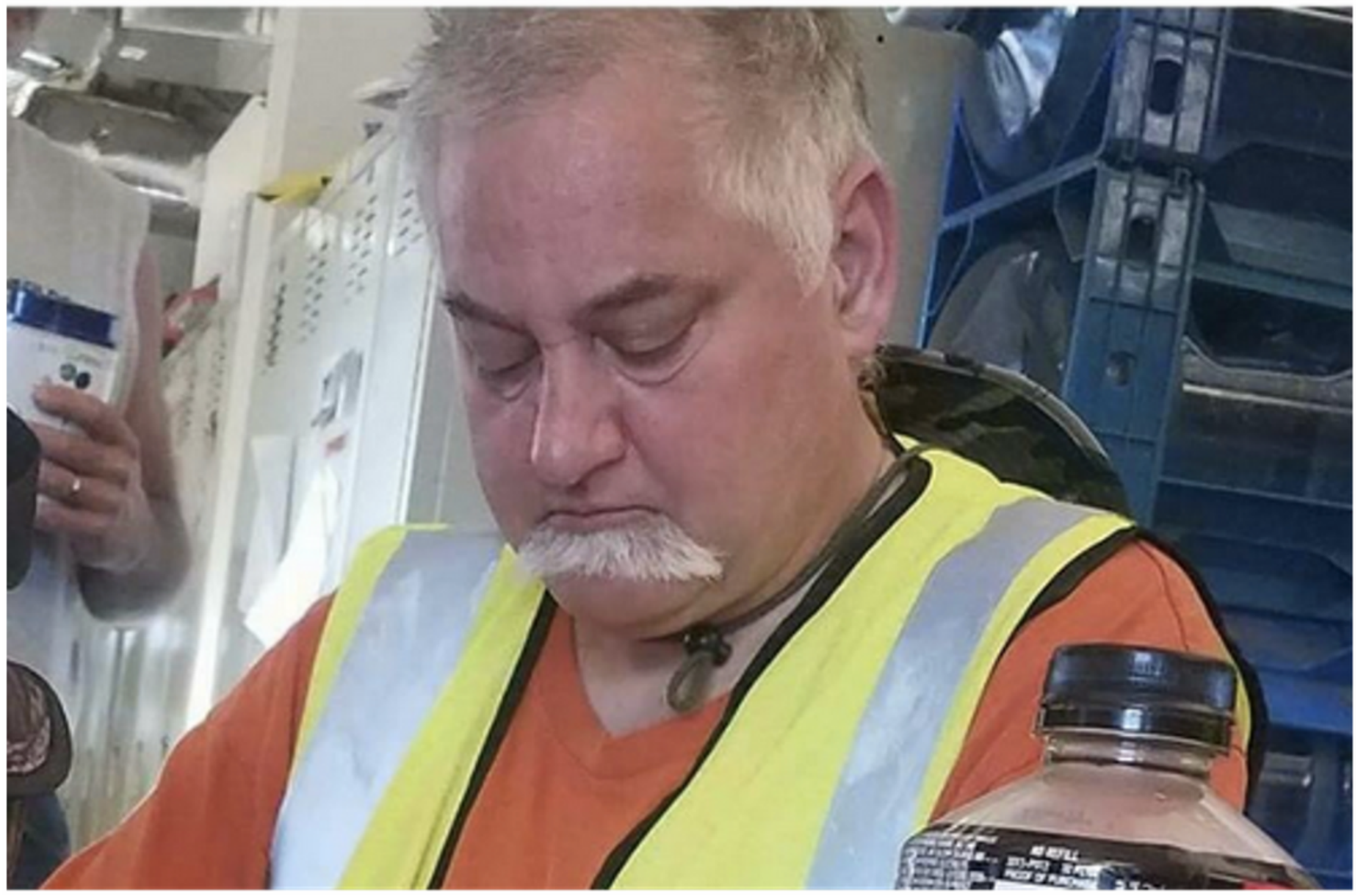

Figure 1

Example of an internet meme. The image used were gathered from the public domain each marked with either the Public Domain Mark 1.0 or CCO 1.0 Universal licence. No alterations were made. Title \& Artist: Unknown. Image Source: Snappygoat. 
A

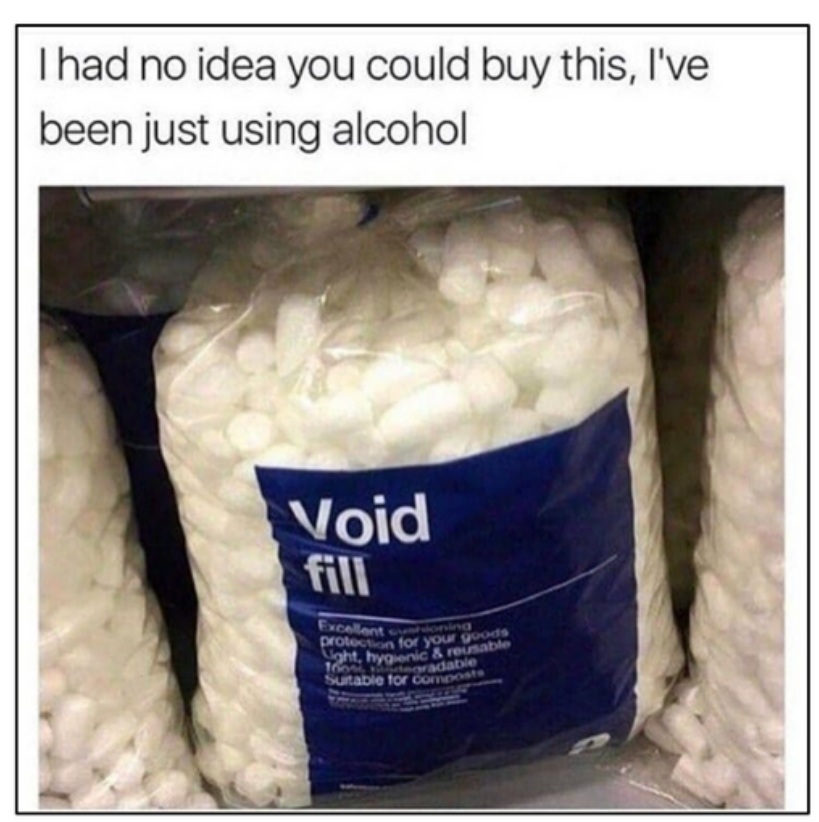

B

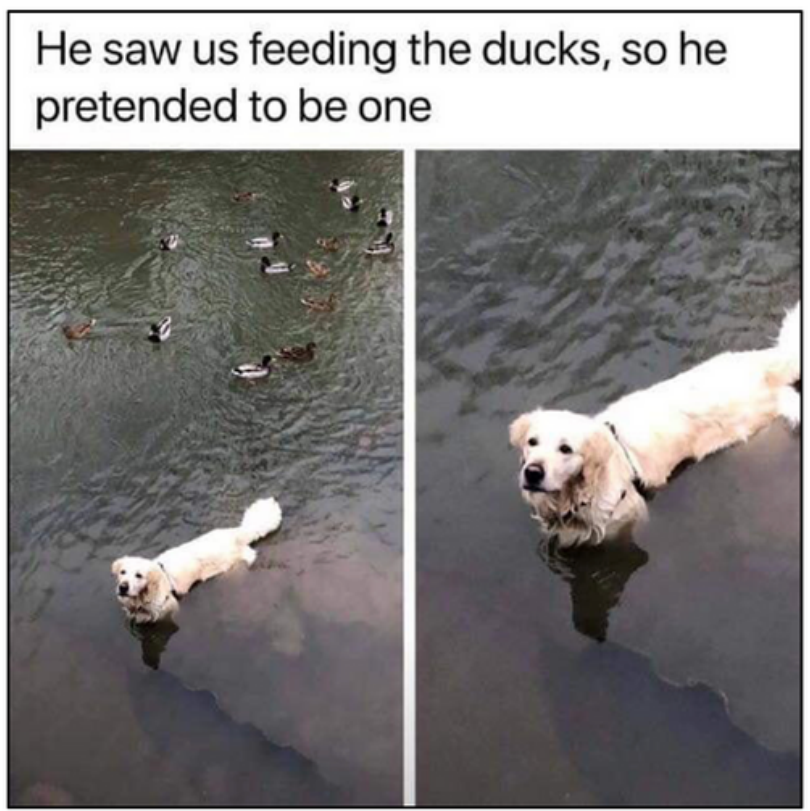

\section{Figure 2}

(A) Example of depressive meme; (B) example of control meme. All images used were gathered from the public domain each marked with either the Public Domain Mark 1.0 or CC0 1.0 Universal licence. No alterations were made. Title \& Artist: Unknown. Image Source: Snappygoat. 